\title{
Roda de conversa: diálogo docente para o acompanhamento do ensino aprendizagem na EJA da Rede Estadual da Bahia
}

\section{Conversation: teacher dialogue for the monitoring of teaching and learning in the EJA of public schools in Bahia}

Adriana de Mello Amorim Novais Silva ${ }^{1}$

Nereida Maria Santos Mafra de Benedictis²

\section{Resumo}

Este artigo visa a apresentar a compreensão da importância do diálogo docente com seus pares para o acompanhamento do processo de ensino-aprendizagem na modalidade EJA. Para isso, buscou-se conhecer o diálogo na teoria freiriana, os princípios teóricos e metodológicos e as orientações para o acompanhamento da aprendizagem na Política da EJA da Rede Estadual da Bahia (2011). Como referencial teórico, utilizaram-se os estudos de Freire (1980, 2013, 2001, 2011) sobre o diálogo, e a discussão sobre a importância da formação do(a) professor(a) embasou-se em Candau (2011), Nóvoa (1992) e Tardif (2006). Para a coleta dos dados, usou-se a roda de conversa com os professores(as) com questões norteadoras, envolvendo o entendimento sobre a EJA, dificuldades de aprendizagem, metodologias positivas e motivos que levaram os(as) educandos(as) a retornarem à escola na modalidade EJA. Com este trabalho, pôde-se perceber a importância dos momentos de diálogo, autêntico, de comunicação e colaboração, entre os professores(as) e seus pares.

Palavras-chave: EJA; Diálogo; Professores(as); Roda de conversa, Ensino-aprendizagem.

\begin{abstract}
This article aims to present the understanding of the importance of teachers' dialogue with their peers for monitoring the teaching-learning process in the Youth and Adult Education. For this, we sought to understand the importance of dialogue in Freirian theory, to know the theoretical and methodological principles and guidelines for monitoring learning in the Youth and Adult Education Policy of the Bahia State (2011). As a theoretical framework, we used the studies about dialogue by Freire (1980, 2013, 2001, 2011), and the discussion about the importance of teacher education was based on Candau (2011), Nóvoa (1992) and Tardif (2006). For data collection, a conversation wheel with teachers was used, with guiding questions, evolving understanding about Youth and Adult Education, learning difficulties, positive methodologies and reasons that led students to return to school in the Youth and Adult Education modality. With this work, it

\footnotetext{
${ }^{1}$ Mestre em Educação pelo Programa de Pós-graduação da UESB (PPGEd). Graduada em Licenciatura em Geografia pela mesma instituição.E-mail: dica_novais@hotmail.com

2 Doutora em Memória, Linguagem e Sociedade. Mestre em Ciências Sociais. Atualmente é professora Adjunta do Departamento de Geografia da Universidade Estadual do Sudoeste da Bahia e Professora do Programa de Pós-graduação em Educação da UESB. E-mail: nereidamafrabenedictis@gmail.com
} 


\section{-Revista de Iniciação à Docência, v.6, n.2, 2021- \\ Publicação: dezembro, 2021 - ISSN 2525-4332}

was possible to notice the importance of moments of dialogue, authentic, of communication and collaboration, between teachers and their pairs.

Keywords: Youth and Adult Education; Dialogue; Teachers; Conversation wheel; Teaching-learning.

\section{Introdução}

Este trabalho tem como objetivo compreender a importância do diálogo docente com seus pares para o acompanhamento do processo de ensino-aprendizagem na modalidade da Educação de Jovens e Adultos (EJA). Para isso, foi necessário conhecer a importância do diálogo na concepção teórica freiriana, as orientações para o acompanhamento da aprendizagem dos sujeitos jovens, adultos e idosos na Política de EJA da Rede Estadual da Bahia, compreender os desafios do processo de ensinoaprendizagem nessa modalidade de ensino e analisar as narrativas dos professores(as) da EJA do Colégio Estadual de Vitória da Conquista.

O interesse por essa temática surgiu de conversas durante as reuniões de Atividade Complementar (AC) com os professores(as) que lecionam na modalidade da EJA. Assim, durante a Semana Pedagógica no ano de 2020, houve um momento para avaliação e diagnóstico sobre o processo de ensino-aprendizagem das turmas da EJA/2019. Nesse diálogo, buscaram-se vestígios sobre 0 entendimento dos professores(as) acerca da EJA, das dificuldades de aprendizagem dos(as) educandos(as), das atividades positivas que desenvolveram nessas turmas e da percepção sobre os motivos que levaram os sujeitos educandos(as) a retornarem ao ambiente escolar.

Para nortear as análises dos dados, utilizou-se a pesquisa no documento base desta modalidade, a Política da EJA da Rede Estadual da Bahia (BAHIA, 2011). Este documento tem como referência a teoria freiriana de educação. Além da pesquisa documental, buscaram-se teóricos que estudam sobre a formação do professor(a), e fezse a pesquisa teórica no tocante ao papel do diálogo na concepção freiriana de educação para embasar os estudos e apresentar as nuances da função do diálogo no processo de ensino-aprendizagem nas turmas da EJA.

No documento base intitulado Política da EJA da Rede Estadual da Bahia (2011), norteador dos trabalhos pedagógicos dos(as) professores(as) dessa modalidade, verificaram-se os espaços de diálogo (BAHIA, 2011) e a importância deste para o processo pedagógico na EJA. Nesse, observou-se a concepção, os princípios teóricosmetodológicos, o perfil e a formação do educador e a orientação para o acompanhamento da aprendizagem.

Nos estudos de Freire (1980, 2013, 2001, 2011), procurou-se compreender o papel da "palavra viva" (FREIRE, 1980, p. 15) para a práxis da Política de EJA da Rede Estadual da Bahia na perspectiva freiriana de educação. Por meio dos estudos de Candau (2011), 


\section{-Revista de Iniciação à Docência, v.6, n.2, 2021- \\ Publicação: dezembro, 2021 - ISSN 2525-4332}

Nóvoa (1992) e Tardif (2006), tivemos o aporte teórico necessário dos trabalhos acerca da formação docente.

Nesse sentido, a roda de conversa foi desenvolvida na perspectiva do diálogo libertador, conversa entre os pares, diálogos sobre a diversidade de experiências pedagógicas nas turmas da EJA. Assim, buscaram-se vestígios nas falas dos(as) professores(as) sobre a importância daquele momento de roda de conversa acerca da EJA. Ressalta-se no processo pedagógico a concepção freiriana de educação para essa política.

Nesse contexto, o presente artigo tem como intuito compreender o papel do diálogo entre os pares, professores(as), para o processo pedagógico e o acompanhamento do ensino-aprendizagem na modalidade de educação para pessoas jovens, adultas e idosas.

\section{O diálogo na concepção teórica e prática freiriana}

O diálogo, na concepção de Freire, é a essência para que haja a verdadeira educação libertadora. $\mathrm{O}$ autor dispõe que:

A palavra viva é diálogo existencial. Expressa e elabora o mundo, em comunicação e colaboração. O diálogo autêntico - reconhecimento do outro e reconhecimento de si, no outro - é decisão e compromisso de colaborar na construção do mundo comum. Não há consciências vazias; por isto os homens não se humanizam, se não humanizando o mundo. (FREIRE, 1980, p. 15)

Para o autor, o diálogo está relacionado à humanização e ao relacionamento entre os pares nos diversos grupos. A participação ativa dos sujeitos em seus meios de convivência implica o diálogo, a oralidade. Assim, apresentar, discutir e argumentar sobre os acontecimentos sociais é importante para os sujeitos envolvidos. Portanto, o diálogo autêntico é essencial no processo de construção e reconstrução das relações sociais e para o processo de ensino-aprendizagem (SILVA, 2020).

A importância do diálogo na concepção de educação freiriana perpassa pelas suas obras. Haddad (2019), em seu livro "O educador um perfil de Paulo Freire", apresenta de forma sucinta e direta as ideias freirianas sobre a importância do processo educativo para a sociedade. Sobre isso, o autor aponta:

Em Educação como prática da liberdade, Paulo Freire elenca os pilares de seu sistema: a não neutralidade da educação; a necessidade de ensinar em favor dos mais pobres; o diálogo como método de educar; a conscientização de educadores e alunos sobre os problemas sociais como via para a transformação da realidade. (HADDAD, 2019, p. 91)

Nessa citação, o autor sistematiza as ideias freirianas sobre a educação. Os pilares, apresentados por Haddad (2019), do processo educativo para Freire discorrem sobre a importância de uma educação libertadora, humanizada e crítica das necessidades sociais. 


\section{-Revista de Iniciação à Docência, v.6, n.2, 2021- \\ Publicação: dezembro, 2021 - ISSN 2525-4332}

Por meio da leitura desses pontos sobre a educação, tece-se algumas considerações, correlacionadas com a importância do diálogo.

No primeiro ponto, em que se discute que a educação não é neutra, há a apresentação de toda a trajetória de vida dos envolvidos, seus posicionamentos sobre os conhecimentos, informações e ações. Há um lugar de escuta por meio do habitus³ (SILVA, 2020) dos envolvidos no processo educativo. Assim, Freire traz a concepção de que a educação depende das necessidades dos envolvidos, se opressores ou oprimidos. Freire (1980, p. 32) apresenta a "Pedagogia que faça da opressão e de suas causas objeto de reflexão dos oprimidos, de que resultará o seu engajamento necessário na luta por sua libertação, em que esta pedagogia se fará e refará". Segundo Freire (1980), o problema é a inercia dos oprimidos em seus espaços de opressão.

O outro ponto traz a questão "para quem a proposta pedagógica foi organizada?"; neste, Freire (1980), em “Pedagogia do Oprimido", apresenta seu posicionamento com relação à "educação bancária", ou seja, os sujeitos educandos(as) recebem os conhecimentos propostos pelo projeto pedagógico elaborados por um grupo, com poder de decisão, ou cultural, ou acadêmica, ou institucional. Portanto,

Na visão "bancária" da educação "saber" é uma doação dos que se julgam sábios aos que julgam nada saber. Doação que se funda numa das manifestações instrumentais da ideologia da opressão - a absolutização da ignorância, que constitui o que chamamos de alienação da ignorância, segundo a qual es se encontra sempre no outro (FREIRE, 1980, p. 67).

Nessa concepção de educação, o(a) professor(a) é o detentor do saber, acadêmico e institucional, e os(as) educandos(as) assimilam os conhecimentos passados como verdadeiros. Freire faz uma crítica a essa educação, afirmando que não se podem transferir valores e conhecimentos sem a participação e reflexão crítica dos envolvidos. Para Freire (1980, p. 35), “A liberdade, que é uma conquista, e não uma doação, exige uma permanente busca”. A aprendizagem não acontece sem a troca entre os envolvidos, professores(as) e educandos(as).

A palavra dita, oralizada, "[...] abre a consciência para o mundo comum das consciências, em diálogo portanto" (FREIRE, 1980, p. 13). Segundo Freire, o diálogo é fundamental para o método de educação sugerido por ele, uma educação humanizadora. Assim, "O diálogo crítico é libertador, por isso mesmo que supõe a ação, tem de ser feito como os oprimidos, qualquer que seja o grau em que esteja a luta por sua libertação" (FREIRE, 1980, p. 56). O diálogo exige troca, do falar e do ouvir, da ação de escuta.

Em seu livro "Pedagogia da autonomia", Freire (2013) apresenta que ensinar exige disponibilidade ao diálogo e conhecer a realidade social dos(as) educandos(as). Dessa forma,

\footnotetext{
$3 \mathrm{O}$ conceito de habitus está ligado à corporificação das disposições socialmente adquiridas, ou seja, as vivências escritas no corpo do indivíduo biológico, aquele que pode levar o indivíduo a viver de acordo com as suas individualidades essenciais, suas subjetividades.
} 


\section{-Revista de Iniciação à Docência, v.6, n.2, 2021- Publicação: dezembro, 2021 - ISSN 2525-4332}

A formação dos professores e das professoras devia insistir na constituição deste saber necessário e que me faz certo desta coisa óbvia, que é a importância inegável que tem sobre nós o contorno ecológico, social e econômico em que vivemos. E ao saber teórico desta influência teríamos que juntar o saber teóricoprático da realidade concreta em que os professores trabalham. (FREIRE, 2013, p. 134)

Freire evidencia a importância da formação humana dos professores(as) para trabalhar nas salas de aula de adultos, e essa concepção pode ser trazida para a educação de jovens, adultos e idosos. Para Freire, na formação do professor(a), é importante conhecer as nuances da educação para adultos, saber que estes sujeitos têm uma trajetória de vida que poderá auxiliar no processo de ensino-aprendizagem. Para além da mediação dos objetos de conhecimento, com metodologias e dinâmicas próprias para esse público, é necessário conhecer a realidade dos(as) educandos(as).

Por meio do diálogo, os professores(as) e educandos(as) irão se desafiar, como diz Freire (2013), a pensar a história social do processo de libertação dos oprimidos e opressores: “Como educador preciso ir 'lendo' cada vez melhor a leitura do mundo que os grupos populares com quem trabalho fazem do seu contexto imediato e do maior de que o seu faz parte" (FREIRE, 2013, p. 78). O sujeito professor(a) precisa ter a habilidade da escuta e leitura do mundo para atuar de forma crítica no processo de ensinoaprendizagem da modalidade de educação para jovens, adultos e idosos.

Em outro momento, Freire (2013) argumenta que o diálogo crítico propicia a troca de saberes, a quebra de barreiras no momento da fala e da escuta. O processo de diálogo libertador precisa fazer parte da prática pedagógica do docente. Na vivência da abertura de trocas de experiências e vivências com o outro, está "[...] a boniteza que há nela como viabilidade do diálogo" (p. 133). Para Freire, "O sujeito que se abre ao mundo e aos outros inaugura com seus gestos a relação dialógica em que se confirma como inquietação e curiosidade, como inconclusão em permanente movimento na história (FREIRE, 2013, p. 133). No momento do diálogo, os sujeitos envolvidos constroem e reconstroem suas memórias, o que influencia em seu habitus. Dessa forma, para Freire, o sujeito está sempre inconcluso e precisa estar ciente da sua inconclusão.

No livro "Medo e ousadia", Freire tece um diálogo com Shor (2001) sobre a educação, no qual explica o conceito de diálogo na sua teoria. Para ele, o diálogo não pode ser entendido como uma técnica para obter informações ou como uma tática para nos aproximar dos(as) educandos(as), mas “[...] algo que faz parte da própria natureza histórica dos seres humanos” (p. 122). Assim,

[...] o diálogo é uma espécie de postura necessária, na medida em que os seres humanos se transformam cada vez mais em seres criticamente comunicativos. $O$ diálogo é o momento em que os humanos se encontram para refletir sobre sua realidade tal como a fazem e re-fazem. (FREIRE; SHOR, 2001, p. 123).

Conforme Freire (2001), o diálogo faz parte da natureza social dos seres humanos; nele, os sujeitos escutam, falam, refletem e constroem ou reconstroem seus saberes, 


\title{
-Revista de Iniciação à Docência, v.6, n.2, 2021- \\ Publicação: dezembro, 2021 - ISSN 2525-4332
}

avaliam suas ações e reavaliam suas posturas. Nessa troca dialógica, "O diálogo sela o ato de aprender, que nunca é individual, embora tenha uma dimensão individual” (p. 14). Desse modo, o processo de ensino-aprendizagem acontece entre os educandos e educadores.

Freire (2011), em seu livro “Pedagogia da Esperança”, apresenta-nos a posição dos envolvidos no processo de ensino-aprendizagem, se professores(as) ou educandos(as), e seus pares. Para Freire,

O diálogo entre professoras ou professores e alunos ou alunas não os torna iguais, mas marca a posição democrática entre eles ou elas. Os professores não são iguais aos alunos por $n$ razões, entre elas porque a diferença entre eles os faz ser como estão sendo. Se fossem iguais, um se converteria no outro. (FREIRE, 2011, p. 162)

Cada um dos envolvidos no processo dialógico tem a sua trajetória de vida, seus conhecimentos, valores, experiências e vivência que os fazem participar desse momento, segundo a sua concepção. Na relação professor(a) e educando(a) e seus pares, há uma relação de troca, cada um com seus saberes participa do processo de ensinoaprendizagem. O diálogo, na concepção freiriana, é indissociável do processo de ensinoaprendizagem, porque é próprio da constituição da natureza humana.

\section{Formação docente para atuar na EJA}

A formação docente para o exercício da profissão de ser professor(a) necessita de uma sólida formação teórico-metodológica nos cursos de licenciatura/graduação, com experiências e vivências no ambiente escolar, por meio de projetos de iniciação à docência e com o estágio supervisionado. Mas, a formação docente pode ser concebida para além da formação inicial, acadêmica, com os currículos e disciplinas, e da formação continuada, por meio dos cursos, e alcança a dimensão do "chão da escola", em uma perspectiva da relação com o outro. Assim,

\begin{abstract}
A formação não se constrói por acumulação (de cursos, de conhecimentos ou de técnicas), mas sim através de um trabalho de reflexividade crítica sobre as práticas e de (re)construção permanente de uma identidade pessoal. Por isso é tão importante investir a pessoa e dar um estatuto ao saber da experiência. (NÓVOA, 1992, p. 13)
\end{abstract}

Na perspectiva de Nóvoa (1992), a formação do professor(a) perpassa pela formação inicial e continuada, por meio de cursos, mas acontece nas relações reflexivas e críticas do seu trabalho no cotidiano escolar e pessoal. Para esse autor, "A formação passa pela experimentação, pela inovação, pelo ensaio de novos modos de trabalho pedagógico. E por uma reflexão crítica sobre a sua utilização" (p. 17). Portanto, o professor(a), a cada vivência e experiência educativa, amplia seu repertório por meio da crítica construtiva do seu trabalho.

Um aspecto importante na formação do ser professor(a) é a dimensão cultural do processo pedagógico. Os envolvidos no processo de ensino-aprendizagem, professor(a) 


\section{-Revista de Iniciação à Docência, v.6, n.2, 2021- \\ Publicação: dezembro, 2021 - ISSN 2525-4332}

e aluno(a), trazem uma bagagem cultural, com vivências, experiências e saberes que os fazem ser quem são; como aponta Freire (2011, p. 162), em "Pedagogia da Esperança", “Os professores não são iguais aos alunos(as) por $n$ razões [...]", e os(as) alunos(as) não são iguais aos professores(as) por várias razões e são diferentes de seus pares. Candau (2011) apresenta-nos:

A dimensão cultural é intrínseca aos processos pedagógicos, "está no chão da escola" e potencializa processos de aprendizagem mais significativos e produtivos, na medida em que reconhece e valoriza a cada um dos sujeitos neles implicados, combate todas as formas de silenciamento, invisibilização e/ou inferiorização de determinados sujeitos socioculturais, favorecendo a construção de identidades culturais abertas e de sujeitos de direito, assim como a valorização do outro, do diferente, e o diálogo intercultural. (CANDAU, 2011, p. 253)

Para Candau (2011), cada sujeito tem a sua trajetória de vida, e essa bagagem cultural precisa fazer parte da dinâmica pedagógica organizada pelos professores(as) para seus educandos(as). Nesse processo, há a significação e ressignificação das aprendizagens no contexto escolar, por meio das relações entre os envolvidos. Portanto, na formação continuada dos(as) professores(as), há a necessidade de abordagens sobre a questão humana, de valorização das vivências e experiências do outro. Há muitos desafios no processo de ensino-aprendizagem na modalidade da EJA; entre eles, está a necessidade de entender os educandos como sujeitos participantes de vários espaços de convivência e que trazem muitos saberes que podem ser utilizados no contexto das aulas.

Os educadores da EJA precisam estar em constante processo de formação. Além de conhecerem e acreditarem na proposta pedagógica dessa modalidade, por Tempos Formativos, é necessário que haja tempos de formação continuada. Segundo Arroyo (2017), os professores/educadores(as) precisam se capacitar para entender a importância da trajetória de vida dos sujeitos educandos(as) para o processo de ensino-aprendizagem na EJA. Pois

O passado pesa com pesado peso sobre suas trajetórias de vida. Não carregam um passado rosado. Nem individual. Dos cursos de formação, os docenteseducadores esperam a capacitação para entender os significados políticos, pedagógicos, formadores e deformadores desses percursos. Não apenas escolares, mas humanos, como membros coletivos. (ARROYO, 2017, p. 29)

A trajetória de vida dos sujeitos educandos(as), com todas as suas vivências e experiências, precisa ser valorizada no processo de ensino-aprendizagem. Assim, o professor(a) deixa de ser "mero espectador destas vivências [...]" (ARROYO, 2017, p. 15) dos educandos(as) e passa a incorporar nos planos pedagógicos as histórias vividas destes sujeitos.

Os momentos de roda de conversa dos professores(as) com seus pares são importantes no processo de formação, uma vez que podem 


\section{-Revista de Iniciação à Docência, v.6, n.2, 2021- Publicação: dezembro, 2021 - ISSN 2525-4332}

[...] prover a troca de experiências entre os(as) professores(as) em exercício na EJA. Esta alternativa de formação continuada, [...] têm papel decisivo no sentido de colocar em diálogo as diferentes informações produzidas no decorrer desta experiência de Educação de Jovens e Adultos no Brasil. (BARCELOS, 2006, p. 92)

Os saberes experienciais, como afirma Tardif (2006), são construções e reconstruções que não provêm das instituições de formação nem de currículos, mas das experiências e vivências no "chão da escola", nos momentos de relação com o outro. Para Tardif (2006, p. 50), "Os saberes experienciais fornecem aos professores(as) certezas relativas a seu contexto de trabalho na escola, de modo a facilitar sua integração". Assim, nos momentos de encontro, reuniões escolares, os professores(as) poderão trocar suas experiências dos momentos em sala de aula da EJA e organizar ou reorganizar suas ações.

\section{Concepção pedagógica da Política da EJA na Bahia}

O documento base da Política de Educação da EJA (2011) apresenta os princípios teórico-metodológicos, o perfil e a formação do educador e a orientação para o acompanhamento da aprendizagem. É uma proposta pedagógica construída por meio da escuta dos envolvidos com essa modalidade e aponta a importância da dialogicidade no processo de ensino-aprendizagem. Nessa concepção pedagógica,

A Educação de Jovens e Adultos deve ser compreendida enquanto processo de formação humana plena que, embora instalado no contexto escolar, deverá levar em conta as formas de vida, trabalho e sobrevivência dos jovens e adultos que se colocam como principais destinatários dessa modalidade de educação. (BAHIA, 2011, p. 11)

No documento base da EJA, observa-se que a trajetória de vida dos sujeitos educandos(as) precisa fazer parte da construção pedagógica organizada pelos professores(as). Ou seja, no momento de elaboração dos planos de aula, da escolha das dinâmicas, dos objetos de aprendizagem e de conhecimento, é necessário conhecer as singularidades dos educandos(as), destinatários dessa modalidade de educação. Assim,

[...] um currículo para a EJA não pode ser previamente definido, se não passar pela mediação com os estudantes e seus saberes, e com a prática de seus professores, o que vai além do regulamentado, do consagrado, do sistematizado em referências do ensino fundamental e do ensino médio, para reconhecer e legitimar currículos praticados. (BAHIA, 2011, p. 13)

Percebe-se que o documento aponta para a importância da participação ativa dos envolvidos na educação para pessoas jovens, adultas e idosas. $O(a)$ professor(a) precisa organizar momentos de escuta sobre a realidade dos sujeitos educandos(as) e, por meio do diálogo, identificar o contexto para o trabalho pedagógico. Nesse sentido, Freire (1980) apresenta a importância do diálogo crítico entre os sujeitos professores(as) e educandos(as):

Para o educador-educando, dialógico, problematizador, o conteúdo programático da educação não é uma doação ou uma imposição - um conjunto de informes a ser depositado nos educandos, mas a revolução organizada, 


\section{-Revista de Iniciação à Docência, v.6, n.2, 2021- Publicação: dezembro, 2021 - ISSN 2525-4332}

sistematizada e acrescentada ao povo, daqueles elementos que este lhe entregou de forma inestruturada. (FREIRE, 1980, p. 98)

No diálogo entre os sujeitos, o professor(a) poderá perceber o contexto e as necessidades com relação às escolhas dos objetos de conhecimento necessários para aquele grupo. Nesse contexto, a escolha dos objetos do conhecimento irá depender do tempo formativo e da organização pedagógica da realidade dos(as) educandos(as).

Os Princípios Teórico-Metodológicos buscam direcionar o trabalho dos professores(as) dessa modalidade. Dentre esses princípios, estão:

1. Reconhecimento dos coletivos de educandos(as) e educadores(as) como protagonistas do processo de formação e desenvolvimento humano. 2. Reconhecimento e valorização do amplo repertório de vida dos sujeitos da EJA: saberes, culturas, valores, memórias, identidades, como ponto de partida e elemento estruturador de todo o estudo das áreas de conhecimento. 3. Processos pedagógicos que acompanhem a formação humana na especificidade do processo de aprendizagem dos sujeitos jovens e adultos. 5. Metodologia adequada às condições de vida dos jovens e adultos e relacionada ao mundo do trabalho, devendo, portanto, possibilitar a problematização da realidade existencial e favorecer o aprender a conhecer e o fazer fazendo. 8. Processo de aprendizagem, socialização e formação, respeitando e considerando a diversidade de vivências, de idades, de saberes culturais e valores dos educandos. 9. Acompanhamento do percurso formativo, com base no princípio da dialogicidade no processo de construção e reorientação do trabalho educativo. 13. Construção e formação de coletivos de educadores(as), com formação própria para a garantia da especificidade do direito à educação dos jovens e adultos. Isto implica na formação inicial e continuada e na definição de critérios específicos de seleção e permanência no coletivo de educadores(as) da EJA.) (BAHIA, 2011, p. 15, grifos nossos)

Os princípios que norteiam o trabalho pedagógico buscam reconhecer a diversidade de trajetórias de vida dos sujeitos educandos(as) e educadores(as), a importância da educação humanizadora, a necessidade da valorização e participação das diversidades no momento de organização das aulas, permeado pelo diálogo crítico entre os envolvidos; e apresentam a importância da formação dos professores(as) que irão trabalhar nas turmas da EJA.

Quanto ao perfil e à formação do educador, este deve

a) ter formação acadêmica ou em serviço com os tempos da juventude e vida adulta; b) conhecer a comunidade em que atua e sua formação: como vivem e trabalham os jovens e adultos; d) comungar com os ideários e exercitar os princípios da Educação Popular; f) construir uma prática dialógica nos espaços, tempos e processos de EJA, considerando os saberes da vida como conteúdos fundantes do processo pedagógico; g) entender e respeitar, de maneira positiva, a diversidade de território, idade, gênero, sexo, raça/etnia, crenças e valores, assumindo-a como elemento pedagógico; h) apresentar projeto de trabalho solidário para intervenção na realidade sociopolítica e cultural dos educandos da EJA. (BAHIA, 2011, p. 16, grifos nossos)

Os(as) professores(as) que irão trabalhar nas turmas da EJA precisam conhecer, entender e acreditar na concepção de educação para pessoas jovens, adultas e idosas, no caso, na Política de EJA da Rede Estadual da Bahia. Portanto, é necessário que tenham 
formação acadêmica e/ou continuada, conheçam a comunidade em que irá lecionar, reconheçam a diversidade de sujeitos, proponham ações que visem à necessidade sociopolítica e cultural dos envolvidos e saibam da importância do diálogo na construção e reconstrução de suas práticas.

Com relação à orientação para o acompanhamento da aprendizagem, os(as) professores(as) devem buscar na concepção de educação os princípios e os pressupostos da Política de EJA da Rede Estadual da Bahia em "Educação de Jovens e Adultos: aprendizagem ao longo da vida". O documento apresenta os critérios para o acompanhamento da aprendizagem, quais sejam:

1. Referendar o acompanhamento do percurso de aprendizagem à luz da concepção de educação, dos princípios e dos pressupostos teóricometodológicos que sustentam este Projeto. 2. Utilizar o diálogo como mediação entre educando(a) e educador(a), para favorecer o acompanhamento do percurso da aprendizagem de forma mais participativa e democrática. 3. Refletir sobre o ato de aprender do(a) educando(a) e do(a) educador(a), valorizando as experiências vividas durante o acompanhamento do percurso da aprendizagem, para dinamizar o processo educativo. 4. Estimular o(a) educando(a) a participar ativamente do acompanhamento do percurso da aprendizagem, de forma a analisar criticamente o seu próprio desenvolvimento para detectar os aspectos em que já avançou e aqueles que carecem de maior estudo; colaborando, assim, para a reorientação do trabalho educativo. 5. Considerar a produção diária do(a) educando(a) como instrumento de coleta de dados, visando à tomada de decisão sobre a reorganização do trabalho educativo. 6. Considerar, no acompanhamento do percurso, sempre que necessário, a reorientação de aprendizagens que ainda não ocorreram, propondo, numa ação consciente, novas alternativas que venham a garantir a aprendizagem de todos(as) os(as) educandos(as). 8. Descrever, através de registros bimestrais, $\mathrm{O}$ acompanhamento do processo de aprendizagem do(a) educando(a). (BAHIA, 2011, p. 19, grifos nossos)

Essa orientação aponta, para os(as) professores(as), o caminho para avaliar a aprendizagem dos sujeitos da EJA. A primeira observação para os educadores é conhecer a concepção e as orientações dessa proposta pedagógica, utilizar o diálogo como meio no processo de ensino-aprendizagem, estimular os sujeitos educandos(as) a participarem ativamente do seu processo de aprendizagem, com observações diárias para avaliações, organização e reorganização do seu trabalho pedagógico.

\section{Roda de conversa: momento de diálogo com professores e professoras da EJA do Colégio Estadual de Vitória da Conquista}

A roda de conversa, segundo AFONSO e Afonso e Abade (2008), é uma metodologia que visa à participação e reflexão dos sujeitos sobre um determinado tema e pode ser utilizada em vários contextos, no caso deste trabalho, no ambiente escolar sobre a modalidade EJA. Essa metodologia foi utilizada para tornar o diálogo fluido, objetivando a participação dos professores(as) com suas experiências, vivências, contribuições, angústias e questionamentos sobre a EJA. Assim, por meio da 
dialogicidade, os(as) professores(as) da EJA puderam discutir algumas questões norteadoras acerca dessa modalidade.

Os professores e professoras que lecionam na EJA em um colégio em Vitória da Conquista, com a práxis em sala de aula, forneceram dados importantes para entendimento do processo de ensino-aprendizagem nessa modalidade de ensino. Contamos com a presença de dez professores e professoras, uma vice-diretora e a diretora.

No primeiro momento, apresentou-se a importância das discussões sobre a EJA durante a Semana Pedagógica 2020. Em seguida, houve a explanação sobre o currículo da EJA para o III Tempo Formativo com seus seis elementos: Eixo Temático, Tema Gerador, Aspectos Cognitivos, Aspectos Socioformativos, Aprendizagens Desejadas e os Saberes Necessários. Tais elementos foram pensados, discutidos e deliberados no coletivo. Houve um momento de rememorar a Matriz Curricular, por quê, como e o que foi trabalhado em sala de aula no ano de 2019, nas turmas da EJA.

Por meio de questões norteadoras, os(as) professores(as) puderam narrar suas experiências. Como a proposta era de uma conversa entre os pares, a participação ocorreu por meio de um questionamento sobre o entendimento da Educação de Jovens e Adultos do colégio de Vitória da Conquista. Com isso, os(as) professores(as) puderam rememoraram suas experiências e narraram:

Prof1, [...] dar a oportunidade a sujeitos que estavam fora da escola [...] determinado tempo da sua vida,

[...] tornaram mães [...] precisaram trabalhar porque perdeu o pai, [...]. O que aconteceu nesse período, nesse meio tempo? A idade avançou, [...] você já imaginou estudar [...] série regular? [...] a própria lei fala que ele tem o direito de estudar.

Prof3, [...] a princípio, a EJA foi criada para maiores de 18 anos, quem tinha essa distorção de idade série [...] Eu já tive aluno que entrou na minha sala que eu precisei pegar na mão com um lápis para que ele conseguisse escrever [...] tinha alunos bem mais interessados, bem mais comprometidos, porque já eram pessoas que trabalhavam, que tinha uma vida lá fora que tinha uma casa, que tinha família, que tinha filhos, que já tinha netos e que vinham para a escola porque tinha vontade mesmo

de aprender, de recuperar alguma coisa que ficou no passado [...] crítica nos últimos anos, [...] abraçando pessoas mais jovens, [...] "enxotado" do regular.

Prof4: [...] Mobral, [...] aceleração 1, 2 e 3. [...] 2009 para 2010 [...] legislação própria, [...] o Tempo Formativo [...] oportunizar às pessoas que tinham saído da escola ou foram excluídas desse espaço escolar na idade certa, mas também na realidade para acabar com a defasagem de série da educação,

[...] não está contando com os analfabetos funcionais.

Prof5: [...] alunos que não têm condições de estar ali. É obrigatório?

Prof4: [...] na realidade não é requisito a sequência, é requisito a escolaridade básica para entrar naquele determinado Eixo, aquele determinado Tempo Formativo.

Prof4: [...] fizeram esse Pró-Jovem [...] veio para o colégio, para fazer o Eixo 4 [...] Eixo 5, 2018 ele fez o Eixo 6 e, em 2019, ele concluiu.

Prof6: [...] comecei a interagir com os alunos da EJA, [...] eles sonhavam em ressurgir para o mundo

lá fora, [...] percebemos que poderíamos realmente fazer alguma coisa por eles. [...] facilitava o nosso trabalho. Ao longo da história, [...] transformações, as modificações no sistema e, consequentemente, a visão de mundo desses alunos foi mudando, porque a inserção de alunos de todo tipo, de todo comportamento que vinham para a sala de aula começou a interferir no processo 


\section{-Revista de Iniciação à Docência, v.6, n.2, 2021- \\ Publicação: dezembro, 2021 - ISSN 2525-4332}

de desenvolvimento desse trabalho, consequentemente, a ação negativa e reação foi criando mais fortalecimento. Enfim, nós passamos a não ter o mesmo entusiasmo. (grifo nosso)

Observando as falas dos(as) professores(as), percebe-se o desconhecimento da proposta pedagógica da EJA do Estado da Bahia; eles reconhecem essa modalidade por meio das reuniões de atividades complementares, das vivências e experiências em sala de aula. Sabem que atende pessoas com distorção idade/série formal, que trabalham e sabem da legalidade dessa proposta. Um dos professores rememorou que esta já passou por várias organizações, desde provas sem aula a propostas pedagógicas de aceleração, diminuição do tempo na escola, o que indica a proposição de oportunidades de regularização da vida escolar dos sujeitos. Outro professor pontuou a falta do desenvolvimento cognitivo dos indivíduos que estão chegando ao Ensino Médio, os quais não apresentam os conhecimentos básicos, como, por exemplo, a escrita; um outro professor questionou se os sujeitos sem esta habilidade poderiam estar naquele Tempo Formativo.

Percebeu-se também a falta de conhecimento a respeito da concepção pedagógica da Educação de Jovens e Adultos e um apego ao processo pedagógico da educação básica seriada. A proposta pedagógica nessa modalidade é voltada para a formação humana; mesmo estando no contexto escolar, as ações do(a) professor(a) devem atender a diversidade de trajetórias de vida encontradas em sala de aula. $O$ objetivo é levar o sujeito à autonomia, à emancipação e à formação da consciência críticoreflexiva em suas relações sociais. Portanto, o(a) professor(a) precisa estar ciente da diversidade de idades, informações, conhecimentos, saberes, desenvolvimentos cognitivos e relações socioafetivas nas diversas turmas da EJA.

Em um segundo momento, os professores(as) foram questionados sobre as dificuldades de aprendizagem identificadas por eles nas turmas do noturno da EJA, e surgiram as seguintes respostas:

Prof5: A falta de base.

Prof7: Leitura e interpretação.

Prof1: Oralidade.

Prof2: Cabedal cultural [...] falta uma visão mais ampla mesmo, de domínio de elementos do que está se passando no mundo.

Prof6: Interação.

Prof1: [...] a gente precisa desmistificar essa questão da arte na escola, [...] a arte vai muito mais além, é a questão do pensamento crítico, da leitura de mundo, da inclusão na escola.

Prof4: [...] foi fantástico, aquele vídeo que você postou dos meninos cantando e tecendo aquelas linhas naquele trabalho, [...] extremamente prazeroso e de terapia, e eles não vêm pra escola, gente,

para absorver tantos conteúdos, que, muitas vezes, a gente quer passar porque a gente está na escola não, eles não vêm pra isso. [...] ele tem consciência que ele não tem uma bagagem de Ensino Médio. Prof1: [...] vai surgindo algo e que alunos chegam pedir: Professora, vamos desenhar hoje? Vocês estão cansados, né? Pais de família, trabalhou o dia inteiro, e aí a possibilidade de fazer o diferente é na aula de artes mesmo, entendeu?

Prof1: Ele vai continuar vendendo o salgadinho dele?

Prof4: Com certeza! E está continuando. (grifo nosso) 


\section{-Revista de Iniciação à Docência, v.6, n.2, 2021- \\ Publicação: dezembro, 2021 - ISSN 2525-4332}

Ao observar as falas dos(as) professores(as) sobre a aprendizagem dos(as) educandos(as) da EJA, entende-se que aqueles analisam a aprendizagem destes por meio das orientações da modalidade seriada. Apresentaram a falta das habilidades e competências da educação básica, a leitura, escrita e interpretação; um professor apresentou a falta de cultura dos(as) educandos(as); e outro criticou essa educação, dizendo que não irá melhorar a vida dos(as) educandos(as) com essa proposta pedagógica.

As orientações para o acompanhamento da aprendizagem dessa modalidade de educação vislumbram essas carências do percurso educativo. Sugerem que o processo de ensino-aprendizagem seja permeado pelo diálogo entre os(as) professores(as) e educandos(as) e entre seus pares. Nesse processo, é necessário buscar e valorizar as diversas culturas, experiências e vivências dos sujeitos educandos na perspectiva de utilizá-las no momento das aulas. Nessa perspectiva, urge estimulá-los a participarem ativamente do seu processo de aprendizagem, com informações, conhecimentos, vivências e experiências na construção dos saberes em sala de aula. Por meio dessa participação, o(a) professor(a) poderá reorganizar suas atividades e reorientar os(as) educandos(as) no processo de aprendizagem. Portanto, as carências cognitivas e de conhecimentos dos sujeitos educandos precisam estar pontuados nos planos pedagógicas dos(as) professores(as), e, para isso, o acompanhamento da aprendizagem pelo professor(a) precisa estar voltado para o crescimento socioafetivo, socioformativo, cognitivo e das aprendizagens desejadas por parte desses sujeitos.

Em outro momento, questionou-se: quais estratégias foram usadas e deram resultado positivo nas turmas da EJA? E se obtiveram as respostas abaixo:

Prof4: Os projetos pedagógicos.

Prof3: Um bingo! [...] Atividade Corrida. Dita responde, dita responde.

Prof10: Música, aula expositiva, você tentando contextualizar [...]

Profg: Experiências do cotidiano [...]

Prof2: [...] música, poesia, [...] teorizar [...] fica muito mais palpável quando traz por exemplo [...]. Profi: Situação problema [...].

Prof2: [...] temas pontuais [...] falas confessionais [...] ela não fala, mas deixa a entender [...] deixa escapar [...] espaço terapêutico, [...] coisas que estavam bem subterrâneas mesmo, e, a partir do momento que vêm à tona, parece que se reorganiza e eles melhoram.

Prof1: [...] percebi [...] eu precisava ouvir mais o meu aluno. Quando eu dei o poder de fala para eles. Eu quero ouvir você falar, todos os dias vocês chegam aqui, eu falo, falo, falo e agora são vocês que vão falar. [...] quando pensa que não, os assuntos vão surgindo, eu falo, cada um foi contando uma história [...]. (grifo nosso)

Os(as) professores(as) pontuaram várias atividades desenvolvidas em sala de aula e que os auxiliaram a mediar os objetos do conhecimento e a avaliar as aprendizagens desejadas. Com essa pergunta norteadora, foram identificadas a variedade de metodologia e dinâmicas que eles mediam em sala de aula. Rememoraram os projetos, bingo, músicas, corrida, situação-problema, falas confessionais e expressaram a importância da contextualização no momento da mediação dos objetos de 


\section{-Revista de Iniciação à Docência, v.6, n.2, 2021- \\ Publicação: dezembro, 2021 - ISSN 2525-4332}

conhecimentos. Um dos professores fez uma análise crítica da sua prática ao afirmar que sentiu a necessidade de ouvir os seus sujeitos educandos.

Nas orientações do acompanhamento da aprendizagem, é proposto o diálogo como meio de mediação entre educador(a) e educando(a) no processo de ensinoaprendizagem. Entende-se o diálogo como troca, do falar e do ouvir, da ação de escuta, e, nesse sentido, o(a) professor(a), no seu planejamento de aula, precisa entender a importância do diálogo existencial, como palavra viva. Assim, na mediação dos objetos de conhecimento por meio de todas as dinâmicas, metodologias, aulas dialógicas, é importante haver o momento de escuta do sujeito educando, uma escuta crítica capaz de entender o outro e reorganizar suas ações educativas.

Por fim, verificaram-se dados sobre a percepção dos(as) professores(as) com relação ao motivo que levou os sujeitos a retornarem à escola. Com essa questão norteadora, buscaram-se vestígios da relação do(a) professor(a) com os sujeitos educandos. As respostas dos(as) professores(as) são apresentadas abaixo:

Prof10: [...] aprender algo que possam utilizar na vida deles, na vida prática deles.

\section{Profg: Praticidade.}

Prof2: Nem sempre, eu acho que eles têm clareza do que querem, [...] querer se reinserir no mundo da vida mesmo, [...] a gente percebe [...] cuida de casa o dia inteiro, ir para a escola pra ela é um bálsamo e outras questões também, o rapaz que está parado e quer galgar um posto melhor do seu emprego, né, quer reconhecimento, quer oxigenar as relações [...]

Prof4: [...] falou: Eu vim aqui porque eu estou precisando fazer uma matrícula, porque eu estou "trabalhando".

Prof11: [...] Só quer saber da notinha, do copiar e escrever [...]

Prof4: [...] acho que a gente está tendo um grande problema na EJA que é [...] assim, é um problema e não é um problema, assim, a gente tem 2 perfis de alunos [...] pessoal mais velho [...] pessoal mais novo [...] evasão maior nessa turma mais nova, [...]

Prof11: [...] quando você faz uma roda de conversa [...] atualidade assim, eles perguntam: pró, e que horas que a gente vai copiar? A gente tem um exercício? Então, assim, tem horas que eles cobram de você uma atividade, um conteúdo, nota, até a nota.

Prof4: [...] pensar em uma proposta, em uma estratégia... para que eles conheçam a EJA. (grifo nosso)

Por meio das falas, percebeu-se que os(as) professores(as) conseguiram abstrair o questionamento e informaram que os sujeitos educandos voltaram para a escola por vários motivos, desde adquirir mais conhecimento, participar criticamente da vida cotidiana, concluir o Ensino Médio até garantir o trabalho. Nas narrativas, alguns professores(as) apresentaram que muitos alunos(as) retornaram à escola somente para o certificado, sem o interesse pelo conhecimento. Outro ponto é que os sujeitos educandos(as) estão habituados a aulas com escrita no quadro ou atividades impressas e não valorizam as discussões orais. Outra percepção dos(as) professores(as) é acerca do perfil dos educandos(as), cujos interesses diferentes, devido à idade, em um mesmo espaço prejudicam o processo de ensino-aprendizagem.

O processo pedagógico da EJA deve visar à formação humana. Portanto, os sujeitos professores(as) precisam organizar suas aulas mediadas pelo diálogo buscando 


\section{-Revista de Iniciação à Docência, v.6, n.2, 2021- \\ Publicação: dezembro, 2021 - ISSN 2525-4332}

conhecer a realidade e as necessidades dos sujeitos educandos e, assim, trazê-los à participação do processo de ensino-aprendizagem. Eles estão matriculados em uma modalidade de educação diferente daquela do seriado, com outra concepção de educação, com tempos e espaços voltados para a autonomia, consciência crítica e reflexiva e tendo o sujeito professor(a) a mostrar o caminho a ser trilhado.

Por meio da Roda de Conversa, pode-se observar a importância desses momentos de diálogo dos professores(as) e seus pares para a formação continuada da docência na modalidade EJA. Os(as) professores(as) puderam ouvir, falar e refletir sobre suas ações em sala de aula da EJA e perceber que as inquietações e ações pedagógicas fazem parte do coletivo. Essa metodologia buscou a participação dos(as) professores(as) de forma a facilitar a comunicação e a interação no intuito de propiciar reflexões sobre a EJA.

\section{Considerações Finais}

No diálogo com os docentes sobre o acompanhamento do ensino-aprendizagem nas suas turmas da EJA, na perspectiva freiriana de ouvir e ser escutado, percebeu-se a importância desses momentos para os(as) professores(as) e seus pares. Cada professor(a) oralizou suas vivências e experiências das turmas em que leciona. Como foi um momento de diálogo, os(as) professores(as) narraram de forma livre e escutaram os colegas como troca de saberes, experiências e possíveis exemplos para suas aulas.

A política de Educação de Jovens e Adultos, que atende também a idosos, visa a garantir a escolarização dos sujeitos com distorção de idade e série. Presumimos, por meio da Roda de Conversa, que os(as) professores(as) têm experiências com a educação da EJA, mas conhecem pouco a proposta pedagógica para essa modalidade e, por isso, apegam-se à prática pedagógica do seriado. Os(as) professores(as) questionaram a falta de conhecimentos básicos, conteúdos prévios, para os(as) educandos(as) estarem naquele tempo formativo, e a falta de saberes culturais no momento das discussões sobre os objetos de conhecimento.

Com o estudo dos princípios teórico-metodológicos da EJA, percebe-se que é importante valorizar o repertório de vida dos(as) educandos(as), seus aspectos cognitivos e socioformativos e buscar mediar as aprendizagens desejadas por meio da contextualização segundo a turma em que leciona e, dessa forma, com a valorização dos saberes dos(as) educandos(as), favorecer a construção e reconstrução das aprendizagens necessárias ao grupo.

Percebe-se a necessidade de momentos de reuniões com diálogos para discussão acerca da concepção pedagógica da EJA com os(as) professores(as). Nessa perspectiva, é preciso levar os professores(as) e seus pares a conhecerem a proposta pedagógica e discutir os desafios do processo de ensino-aprendizagem na modalidade da Política de EJA da Rede Estadual da Bahia. 
Em conformidade com as dificuldades apontadas pelos docentes, pode-se sugerir uma política de formação inicial com disciplinas voltadas para o ensino-aprendizagem de jovens, adultos e idosos, com oportunidade de práxis em salas de aula dessa modalidade, além de formação continuada, permanente, para os(as) professores(as) que irão trabalhar com o público da EJA.

\section{Referências}

AFONSO, M. L.; ABADE, F. L. Para reinventar as rodas: rodas de conversa em direitos humanos. Belo Horizonte: RECIMAM, 2008.

ARROYO, Miguel G. Passageiros da noite do trabalho para a EJA. Petrópolis: Vozes, 2017. BAHIA. SECRETARIA DE EDUCAÇÃO. Política de EJA da Rede Estadual: EJA Educação de Jovens e Adultos Aprendizagem ao longo da vida. Salvador: SEC-BA, 2011.

BARCELOS, V. Formação de professores para educação de jovens e adultos. Petrópolis, RJ: Vozes, 2006.

CANDAU, Vera Maria Ferrão. Diferenças culturais, cotidiano escolar e práticas pedagógicas. Currículo sem Fronteiras, v.11, n.2, pp.240-255, Jul/Dez 2011. Disponível em: https://saopauloopencentre.com.br/wp-content/uploads/2019/05/candau.pdf. Acesso em: 30.08.2021.

FREIRE, Paulo. Educação como prática da liberdade. $19^{\mathrm{a}}$ ed. Rio de Janeiro: Paz e Terra, 1989.

FREIRE, Paulo. Pedagogia da Autonomia: saberes necessários à prática educativa. $44^{\mathrm{a}} \mathrm{Ed}$. Rio de Janeiro: Paz e Terra, 2013.

FREIRE, Paulo. Pedagogia da Esperança: um reencontro com a Pedagogia do Oprimido. $3^{\mathrm{a}}$ ed. São Paulo: Paz e Terra, 2011.

FREIRE, Paulo. Pedagogia do Oprimido. $8^{\text {a }}$ Ed. Rio de Janeiro: Paz e Terra, 1980.

FREIRE, Paulo; et al. Medo e ousadia: o cotidiano do professor. $9^{\text {a }}$ ed. Rio de Janeiro: Paz e Terra, 2001.

HADDAD, Sérgio. O Educador: um perfil de Paulo Freire. São Paulo: Todavia, 2019.

NÓVOA, António. Formação de professores e profissão docente. In: NÓVOA, António(org.) Os professores e a sua formação. Lisboa: Dom Quixote, 1992. ISBN 972-201008-5. pp. 13-33. Disponível em: https://repositorio.ul.pt/handle/10451/4758?mode=full. Acesso em: 30.08 .2021

SILVA, Adriana de Mello Amorim Novais. Trajetória de vida dos sujeitos da EJA e o papel dos saberes geográficos para a emancipação social. 2020. 220f. Dissertação (Mestrado em Educação) - Programa de Pós-Graduação em Educação, Universidade Estadual do Sudoeste da Bahia, Vitoria da Conquista, Bahia, 2020.

TARDIF, Maurice. Saberes docentes e formação profissional. $7^{a}$ Edição. Petrópolis, RJ: Vozes, 2006. 